\title{
Involvement of adenosine A1 receptor in electroacupuncture-mediated inhibition of astrocyte activation during neuropathic pain
}

\author{
Envolvimento do receptor de adenosina A1 na inibição da ativação de astrócitos mediada \\ por eletroacupuntura durante a dor neuropática
}

Mingxiao Zhang', Qinxue Dai', Dongdong Liang', Dan Li1, Sijia Chen'1, Shuangdong Chen', Kunyuan Han', Luping Huang', Junlu Wang

\begin{abstract}
Neuropathic pain is a chronic pain condition caused by damage or dysfunction of the central or peripheral nervous system. Electroacupuncture (EA) has an antinociceptive effect on neuropathic pain, which is partially due to inhibiting astrocyte activation in the spinal cord. We found that an intrathecal injection of 8-cyclopentyl-1,3-dipropylxanthine (DPCPX), a selective adenosine A1 receptor antagonist, reversed the antinociceptive effects of EA in a chronic constriction injury-induced neuropathic pain model. The expression of GFAP in L4-L6 spinal cord was significantly upgraded, while DPCPX suppressed the effect of the EA-mediating inhibition of astrocyte activation, as well as wiping out the EA-induced suppression of cytokine content (TNF- $\alpha$ ). These results indicated that the adenosine A1 receptor is involved in EA actions during neuropathic pain through suppressing astrocyte activation as well as TNF- $\alpha$ upregulation of EA, giving enlightenment to the mechanisms of acupuncture analgesia and development of therapeutic targets for neuropathic pain.
\end{abstract}

Keywords: Electroacupuncture; astrocytes; receptor, adenosine A1; cytokines, neuralgia.

RESUMO

A dor neuropática é uma condição de dor crônica causada por dano ou disfunção do sistema nervoso central ou periférico. A eletroacupuntura (EA) tem um efeito antinociceptivo durante a dor neuropática, que é parcialmente devido à inibição da ativação de astrócitos na medula espinhal. Descobrimos que a injeção intratecal de 8-ciclopentil-1,3-dipropilxantina (DPCPX), um antagonista seletivo do receptor de adenosina A1, reverteu os efeitos antinociceptivos da EA no modelo de dor neuropática induzida por lesão por constrição crônica (CCI). A expressão da GFAP na medula espinal L4-L6 foi significativamente melhorada, enquanto a DPCPX suprimiu o efeito da inibição mediadora da EA na ativação de astrócitos, bem como eliminou a supressão induzida pela EA do conteúdo de citocina (TNF- $\alpha$ ). Esses resultados indicam que o receptor de adenosina A1 está envolvido nas ações da EA durante a dor neuropática, suprimindo a ativação astrocitária, bem como o aumento da TNF- $\alpha$ na EA, fornecendo esclarecimentos sobre os mecanismos de analgesia da acupuntura e o desenvolvimento de alvos terapêuticos para dor neuropática.

Palavras-chave: Eletroacupuntura; astrócitos; receptor A1 de adenosina; citocinas; neuralgia.

Neuropathic pain is a chronic pain condition caused by damage or disease of the somatosensory nervous system ${ }^{1}$. The presence of neuropathic pain negatively impacts the quality of life. The current treatment for neuropathic pain is challenging. Pharmacological interventions are by far the most commonly used in clinics, but the clinical efficacy has not been satisfactory $y^{2,3}$. Therefore, an effective and safe treatment strategy for neuropathic pain is desirable. The World Health
Organization has reported that acupuncture has shown therapeutic effects in certain diseases, symptoms or conditions, including several types of pain ${ }^{4}$. Both manual acupuncture and electroacupuncture (EA) have been widely used to ameliorate diverse pain, particularly in the treatment of chronic pain. The mechanisms of acupuncture analgesia have been widely studied, but the exact molecular mechanisms are not fully defined.

${ }^{1}$ The First Affiliated Hospital of Wenzhou Medical University, Department of Anesthesiology, Wenzhou, 325000, China.

Correspondence: Junlu Wang; Department of Anesthesiology, The First Affiliated Hospital of Wenzhou Medical University; Shangcai village, Nanbaixiang, Ouhai District, Wenzhou, Zhejiang, China.325000; E-mail:wangjunlu973@yeah.net

Conflict of interest: There is no conflict of interest to declare.

Support: This work was supported by the grants from the Natural Science Foundation of China (No. 81573742, No. 81704180 and No. 81803937) and Wenzhou Public Welfare Science and Technology Plan (No. Y20170268).

Mingxiao Zhang and Qinxue Dai have contributed equally to this work.

Received 28 April 2018; Accepted 03 July 2018; Accepted 29 July 2018 
Adenosine is a purine nucleoside that can signal through four distinct receptors (A1R, A2AR, A2BR and A3R $)^{5}$. The adenosine $\mathrm{A} 1$ receptor $(\mathrm{A} 1 \mathrm{R})$ has been shown to play an essential role in pain sensation with analgesic effects and is expressed in astrocytes, which contribute substantially to the neuropathic pain maintenance ${ }^{6}$. Adenosine regulates the synthesis and secretion of cytokines ${ }^{7,8}$ and impacts astrocyte proliferation ${ }^{9}$.

In the current study, we hypothesized that A1R plays a key role in EA-mediated inhibition of astrocyte activation. We investigated the relationship between A1R and EA in a rat sciatic nerve chronic constriction injury (CCI) model.

\section{METHODS}

\section{Animals and group assignment}

Male Sprague-Dawley rats (200-250 g) were purchased from the Animal Center of Wenzhou Medical University. Protocols involving the use of the animals were approved by the Wenzhou Medical University Animal Policy and Welfare Committee (approval documents: wydw2014- 0001), and all procedures were designed to minimize discomfort in the animals.

The 33 animals were randomly divided into six groups ( $n$ = 5-7): (1) Sham-CCI group, received sham CCI surgery; (2) CCI group, received CCI surgery; (3) CCI+EA group, received $\mathrm{CCI}$ surgery, and $\mathrm{EA}$ treatment on day seven after CCI; (4) CCI+8-cyclopentyl-1,3-dipropylxanthine (DPCPX) group, received CCI surgery, and intrathecal injection of DPCPX on day seven after CCI; (5) CCI+DPCPX+EA group, received CCI surgery, and intrathecal injection of DPCPX followed by EA on day seven after CCI; and (6) CCI+dimethyl sulfoxide (DMSO)+EA group, received CCI surgery, and intrathecal injection of solvent control DMSO, followed by EA on day seven after the CCI.

The CCI surgery was performed one day before baseline threshold testing. Thermal hyperalgesia and mechanical allodynia were measured on day seven after CCI. After that, rats in the CCI+DPCPX, CCI+DPCPX+EA and CCI+DMSO+EA groups received an intrathecal injection of DPCPX or DMSO respectively; EA was applied 30 minutes after intrathecal injection. The pain threshold was measured again 60 minutes after EA.

\section{Chronic constriction injury model}

To build a neuropathic pain model, we followed Bennett and Xie's protocol ${ }^{10}$. Briefly, rats were anesthetized with $10 \%$ chloral hydrate $(0.3 \mathrm{~g} / \mathrm{kg}$, ip). The sciatic nerve of the right hind leg was exposed by blunt dissection through the biceps femoris. Four chromic gut ligatures were tied loosely around the sciatic nerve at $1 \mathrm{~mm}$ intervals. We used sham surgery (exposure of the sciatic nerves without ligation) as the Sham-CCI control group.

\section{Electroacupuncture treatment}

Two acupuncture needles, $0.25 \mathrm{~mm}$ in diameter, were inserted into the right hind leg, one in the Zusanli point (St 36, $5 \mathrm{~mm}$ lateral to the anterior tubercle of the tibia), and the other in the Taichong point ( $\operatorname{Lr} 3$, at the junction of the first and second metatarsal bones on the dorsum of the foot). Electrical stimulation was applied using G6805-AII acupuncture stimulation machine (Medical Equipment Factory, Shanghai Medical Instruments, Shanghai, China) for 30 minutes, with $1 \mathrm{~mm}$ intensity and $2 / 15 \mathrm{~Hz}$ frequency ${ }^{11}$. The rats were under anesthesia and placed into individual plastic cages with a glass bottom.

\section{Intrathecal drug delivery}

Intrathecal catheter implantation was performed as previously published ${ }^{12}$. Briefly, rats were anesthetized with $10 \%$ chloral hydrate $(0.3 \mathrm{~g} / \mathrm{kg}$, ip). An intrathecal catheter (PE-10 tube) was inserted between the L4 and L5 vertebrae and extended to the subarachnoid space of the lumbar enlargement; $7 \mu \mathrm{L} 2 \%$ lidocaine and $10 \mu \mathrm{L}$ saline were injected into the catheter after surgery. Temporary paralyzation in both hind legs indicated the correct catheterization.

Rats were allowed to recover for three days before all the procedures. Fifteen animals with motor impairment from the intrathecal catheterization were excluded from the study.

For intrathecal administration, the drugs were administered slowly by a microinjection syringe in a volume of $10 \mu \mathrm{L}$, followed by a $10 \mu \mathrm{L}$ saline wash. For the DPCPX injection, DPCPX (Sigma-Aldrich, USA) was dissolved in 10\% DMSO (Sigma-Aldrich, USA) $(10 \mu \mathrm{g} / 10 \mu \mathrm{L})$.

\section{Assessment of hypersensitivity}

All pain threshold measurements were performed between 8 a.m. and 5 p.m., and the room temperature was $20-24^{\circ} \mathrm{C}$.

\section{Mechanical allodynia}

The rats were placed into an individual plastic cage with a wire mesh bottom, 20 minutes before testing. An electronic von Frey anesthesiometer (IITC Life Science, USA) was used to test the tactile threshold in the right hind paw. The probe was positioned underneath the mid-plantar surface of the hind paw (area between the third and fourth toe). The probe perpendicularly stimulated the plantar surface of the hind paw with increasing force. Brisk withdrawal or paw flinching was considered a positive response, and the paw withdrawal threshold was recorded. A cutoff value of $50 \mathrm{~g}$ was enforced to prevent tissue damage. The test was repeated three times at five-minute intervals and the mean value was calculated.

\section{Thermal hyperalgesia}

Thermal hyperalgesia was assessed in unrestrained rats as previously published ${ }^{13}$. A 336 Plantar Test Apparatus and Tail Flick Test Analgesia Meter (IITC Life Science, USA) were 
used. The rats were placed into an individual plastic cage with a glass bottom 20 minutes before the test. The device was activated after placing the stimulator directly beneath the plantar surface of the hind paw. The paw withdrawal latency in response to radiant heat was recorded. A cutoff time of 25 seconds was enforced to prevent tissue damage. The paw withdrawal latency was recorded and averaged over three times at five-minute intervals.

\section{Immunohistochemistry}

Once the behavior test after EA treatment was completed, rats were anesthetized with $10 \%$ chloral hydrate $(0.3$ $\mathrm{g} / \mathrm{kg}$, ip), and perfused transcardially with $200 \mathrm{ml}$ saline, followed by $200 \mathrm{ml}$ ice-cold $4 \%$ paraformaldehyde in $0.1 \mathrm{M}$ phosphate buffer ( $\mathrm{pH}$ 7.4). The lumbar enlargement (L4-L6) of the spinal cord was dissected. After dehydration, tissues were embedded in paraffin, and cut into $4 \mu \mathrm{m}$ sections.

Antigen retrieval was performed. After exposure to $0.3 \%$ hydrogen peroxide and blocking, the sections were incubated sequentially with GFAP antibody (1:1000) (ab7260, Abcam, UK) overnight at $4^{\circ} \mathrm{C}$, biotinylated goat anti-rabbit secondary antibody, and avidin-biotin peroxidase complex for 30 minutes at room temperature. Bound peroxidase was visualized after incubation with $0.05 \%$ diaminobenzidine under microscope in three minutes and the sections were rinsed with water. The sections were stained with eosin. After gradient alcohol dehydration and xylene transparent, the sections were mounted with neutral gum and examined under optical microscopy. Image-Pro Plus 6.0 software was used to analyze the integrated optical density of GFAP-positive cells.

\section{Protein extraction}

Once the behavior test after EA treatment was finished, and rats had been anesthetized with $10 \%$ chloral hydrate $(0.3$ $\mathrm{g} / \mathrm{kg}$, ip), the right dorsal horn of the lumbar enlargement (L4-L6) was dissected and immediately homogenized in icecold RIPA lysis buffer (R0020, Solarbio, China), with $1 \mathrm{mM}$ phenylmethylsulfonyl fluoride, $1 \mathrm{mM}$ phosphatase, and proteinase inhibitors (EDTA-free protease inhibitor cocktail, Roche, USA). The homogenates were centrifuged at 14,000 g for 15 minutes at $4^{\circ} \mathrm{C}$, and the supernatant was collected. The protein concentration was measured using a BCA assay kit (Pierce Biotechnology).

\section{Western blotting}

Total $50 \mu \mathrm{g}$ in each sample was boiled for three minutes in SDS-polyacrylamide gel electrophoresis sample buffer and subjected to SDS-polyacrylamide gel electrophoresis using $10 \%$ running gels and transferred onto polyvinylidene difluoride membranes. The membranes were blocked with $5 \%$ bovine serum albumin in Tris-buffered saline with Tween 20 (50 mM tris- $\mathrm{HCl}$ at $\mathrm{pH} 7.5,150 \mathrm{mM} \mathrm{NaCl}$, and $0.1 \%$ Tween 20) for one hour at room temperature and then incubated overnight at $4^{\circ} \mathrm{C}$ with primary antibody $(1: 1,000)$ (ab7260,
Abcam, UK). A peroxidase-conjugated goat anti-rabbit antibody $(1: 10,000)$ was used as the secondary antibody. The blots were examined with the lightening chemiluminescence kit (Piece). For analysis, the films were scanned and the optical density of specific bands was measured with quantity one protein $4.2 \beta$-actin was used as a loading control.

\section{ELISA}

The levels of IL-6, TNF- $\alpha$ and IL-1 $\beta$ expression in the spinal dorsal horn were tested following the manual instruction of ELISA kits (rat IL-6 ELISA kit, 10403R-09; rat TNF- $\alpha$ ELISA kit, 10359R-09; rat IL-1 $\beta$ ELISA kit, 10623R-09, Shanghai Boyun Biotech Co., Ltd., China). In brief, a 96-well plate was filled with $50 \mu \mathrm{l}$ serially-diluted standards together with $50 \mu \mathrm{l}$ streptavidin-HRP, which were used to plot standard curves; and $40 \mu$ test samples together with $10 \mu \mathrm{l}$ antibody and $50 \mu \mathrm{l}$ streptavidin-HRP were added in triplicates. After gentle mixing, the plate was incubated for 60 minutes at $37^{\circ} \mathrm{C}$. The plate was held in washing buffer five times. Chromogenic substrates $\mathrm{A}$ and $\mathrm{B}$ were sequentially added ( $50 \mu \mathrm{l}$ each) into each well, followed by incubation in the dark for 10 minutes at $37^{\circ} \mathrm{C}$. Then $50 \mu$ quenching buffer was added to each well. Absorbance (OD values) at $450 \mathrm{~nm}$ wavelength was measured by a microplate reader within 10 minutes, after adding the quenching buffer. A linear regression model was plotted based on the concentration of standards and respective OD values.

\section{Statistical analysis}

Values were represented as means \pm SEM. The GraphPad Prism was used for statistical analysis. Two-way ANOVA followed by Bonferroni post hoc tests were used for behavioral data. One-way ANOVA followed by Newman-Keuls post hoc tests were used for immunohistochemistry, western blotting and ELISA data. The unpaired t test was used for ELISA data between the CCI+DPCPX+EA and CCI+DMSO+EA groups. Statistical significance was considered at $\mathrm{p}<0.05$.

\section{RESULTS}

Effects of DPCPX on the antinociceptive action of EA

The paw withdrawal threshold (PWT) did not differ from the baseline in the Sham-CCI group ( $p>0.05)$. For the other groups, the PWT significantly decreased compared to the baseline, and was significantly lower than the ShamCCI group on day seven $(p<0.01)$, suggesting that mechanical allodynia occurred after CCI surgery. For animals in the CCI+EA group $(33.43 \pm 4.97)$, the PWT was significantly higher than animals in the CCI group (23.04 \pm 2.92$)$, indicating that EA treatment attenuated the mechanical allodynia induced by CCI (Figure 1A and B). 
A

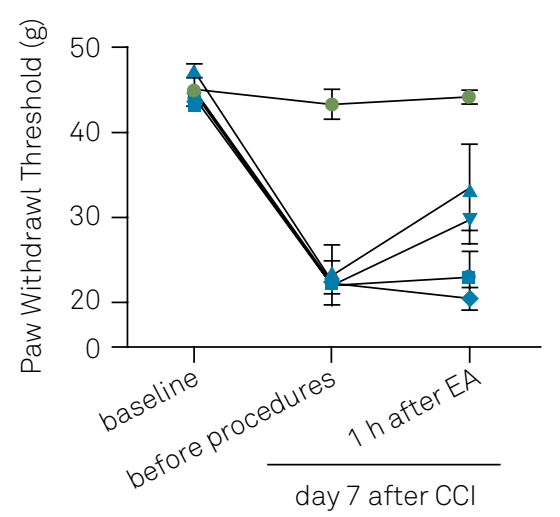

C

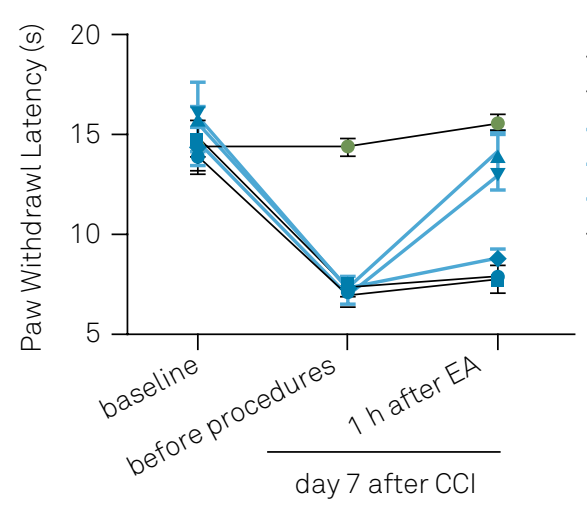

B
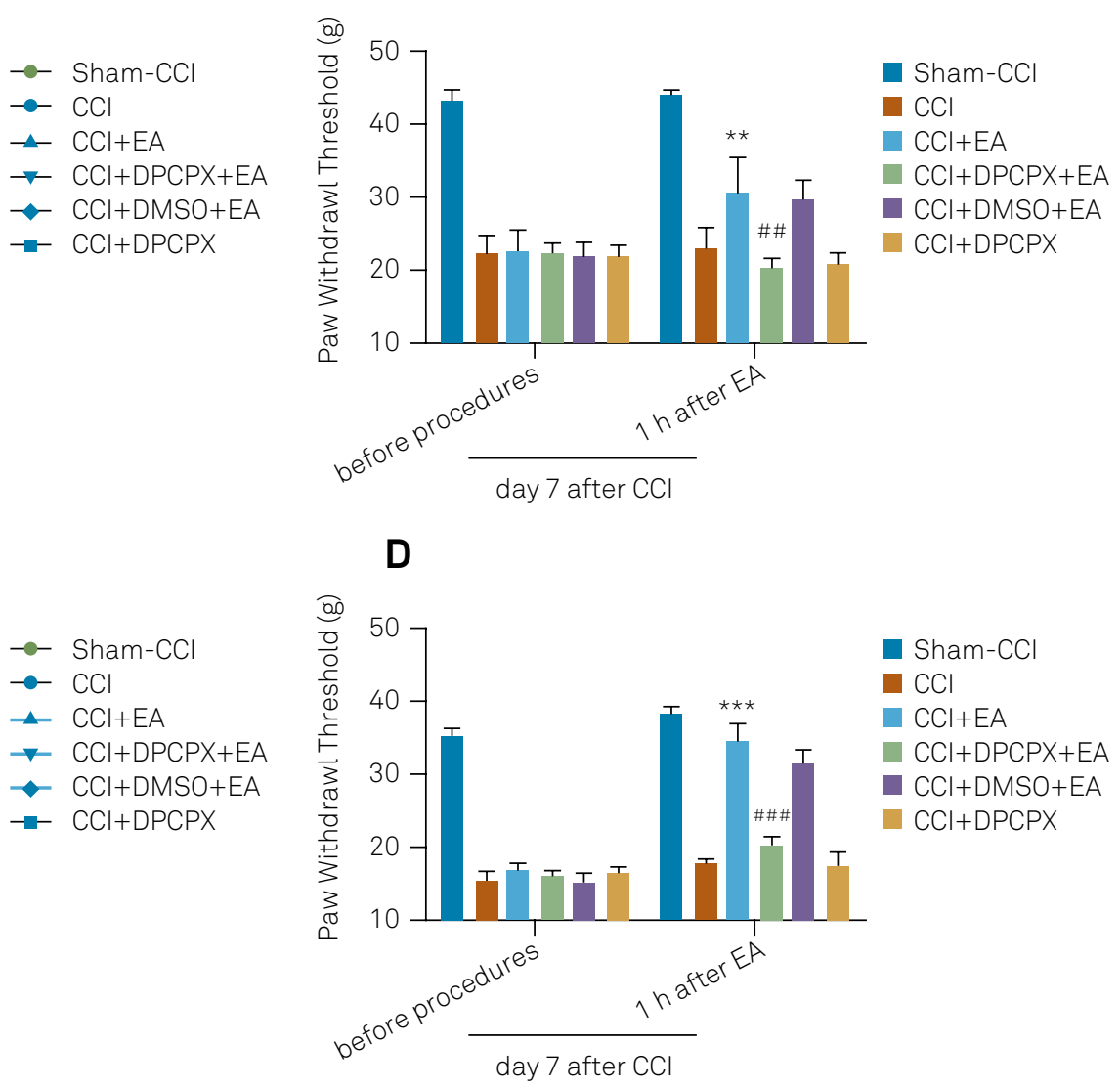

Figure 1. Effects of intrathecal injection of DPCPX on the antinociceptive action of EA. (A) Time course of the paw withdrawal threshold to tactile stimulation of the right hind paw before and after $\mathrm{CCl}$. (B) The paw withdrawal threshold to tactile stimulation of the right hind paw on day seven after $\mathrm{CCl}$, before the procedures (intrathecal injection and EA) and one hour after EA. (C) Time course of paw withdrawal latency to thermal stimulation of the right hind paw before and after CCI. (D) The paw withdrawal latency to thermal stimulation of the right hind paw on day seven after $\mathrm{CCl}$, before procedures (intrathecal injection and EA) and one hour after EA. The values are presented as means \pm SEM. $\left({ }^{* *} p<0.01,{ }^{* * *} p<0.001\right.$ compared with the CCI group; ${ }^{* \#} p<0.01$, \#\#\# $\mathrm{p}<0.001$, compared with the CCI+DMSO+DPCPX group).

The administration of DPCPX before EA significantly lowered the PWT in the right hind paw $(20.38 \pm 1.37$ in the CCI+DPCPX+EAgroup and $29.72 \pm 2.90$ in the CCI+DMSO+EA group, $\mathrm{p}<0.01$, Figure $1 \mathrm{~A}$ and $\mathrm{B}$ ). These results indicated that DPCPX was able to blunt the antinociceptive effect of EA. The animals in the CCI+DPCPX group $(20.75 \pm 1.61)$ and CCI group (23.04 \pm 2.92$)$ did not show any differences in the PWT in the right hind paw ( $p>0.05$ ), suggesting that intrathecal injection of DPCPX alone did not influence CCI-induced mechanical allodynia (Figure 1A and B). Similar changes were observed in the paw withdrawal latency in response to thermal stimulation (Figure 1C and D).

\section{Changes in GFAP expression in L4-L6 spinal cord}

Increased expression of GFAP represents astrocyte activation. Stronger GFAP immunoreactivity was observed in the CCI group $(0.0392 \pm 0.0069)$ compared with the ShamCCI group $(0.0087 \pm 0.0023, p<0.01)$, suggesting that CCI induced astrocyte activation (Figure $2 \mathrm{~A}, \mathrm{~B}$ and $\mathrm{G}$ ). The GFAP in the CCI+EA group $(0.0126 \pm 0.0009)$ exhibited less intense staining compared to the CCI group ( $\mathrm{p}<0.01$ ), suggesting that $\mathrm{EA}$ attenuated $\mathrm{CCI}$-induced astrocyte activation (Figure 2B, $\mathrm{C}$ and $\mathrm{G}$ ). The expression of GFAP was significantly increased in the CCI+DPCPX+EA group $(0.0314 \pm 0.0011)$ compared with the vehicle control group $(0.0193 \pm 0.0010$ in the CCI+DMSO+EA group, $\mathrm{p}<0.01$ ), suggesting that intrathecal injection of DPCPX reversed the effect on the astrocyte activation of EA (Figure 2D, E and G). There was no significant difference in GFAP expression patterns between the CCI group and CCI+DPCPX group (0.0338 $\pm 0.0057, \mathrm{p}>0.05)$, suggesting that DPCPX alone did not influence GFAP expression pattern after CCI (Figure 2B, F and G).

Expression of GFAP was significantly upregulated in the CCI group ( $3.61 \pm 0.59)$ in comparison to the Sham-CCI group $(1.35 \pm 0.14, \mathrm{p}<0.05)$. In sharp contrast, the CCI+EA group $(1.46 \pm 0.15)$ showed significant decrease in GFAP expression compared with the CCI group $(\mathrm{p}<0.05)$. The expression level of GFAP was significantly elevated in the CCI+DPCPX+EA group $(3.15 \pm 0.47)$ compared with the CCI+DMSO+EA group (1.45 \pm 0.17$)$, but the CCI+DMSO+EA and CCI+EA groups 
A

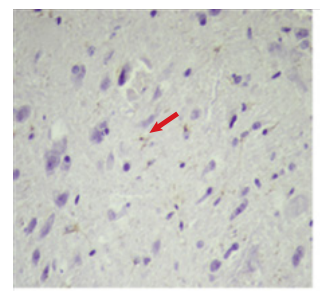

D Sham-CCl

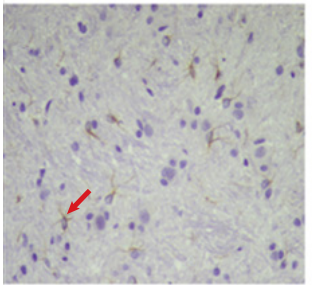

$\mathrm{CCl}+\mathrm{DPCPX}+\mathrm{EA}$
B

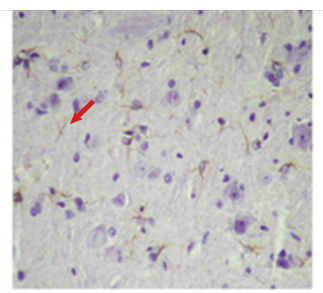

E

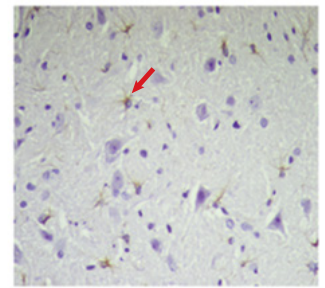

$\mathrm{CCl}+\mathrm{DMSO}+\mathrm{EA}$
C

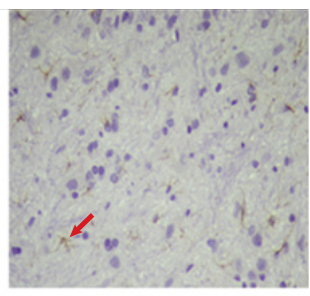

F $\quad \mathrm{CCl}+\mathrm{EA}$

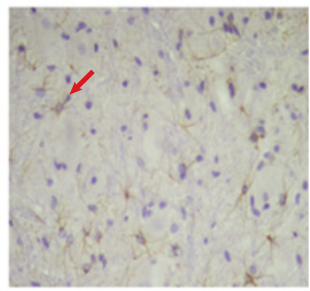

CCI-DPCPX

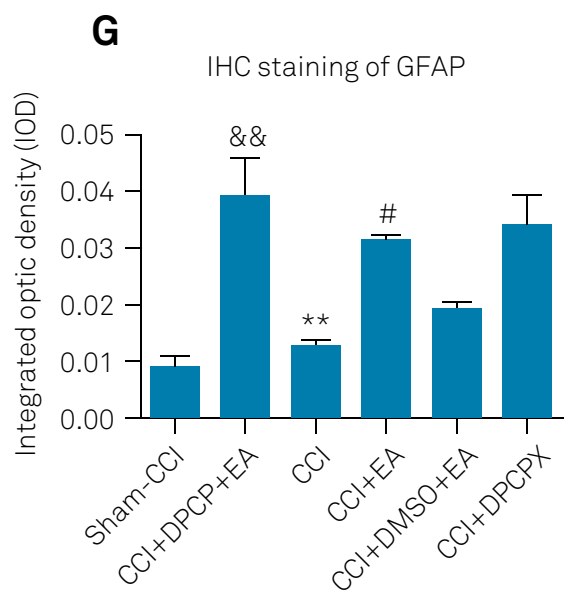

Figure 2. Changes in GFAP immunoreactivity in L4-L6 spinal dorsal horn after different treatments on day seven after CCI. Representative immunohistochemistry image showing the expression of GFAP in L4-L6 spinal dorsal horn after (A) Sham-CCI, (B) $\mathrm{CCl}$, (C) CCI+EA, (D) CCI+DPCPX+EA, (E) CCI+DMSO+EA and (F) CCI+DPCPX on day seven after CCI. Red arrows indicate characteristic cells. (G) Average integrated optical density of GFAP positive cells in the spinal dorsal horn after different treatments. Data are presented as mean \pm SEM. ( ${ }^{\&} \& p<0.01$, compared with the Sham-CCI group; **p $<0.01$, compared with the CCI group; ${ }^{\mathrm{p}} \mathrm{p}<0.05$, compared with the CCI+DMSO+DPCPX group). Scale bar: $100 \mu \mathrm{m}$.

A

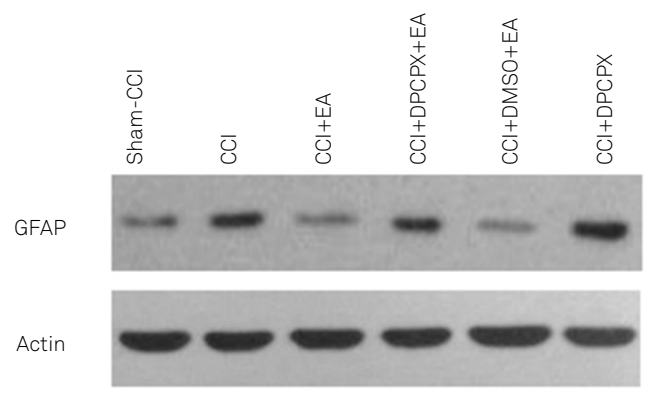

B

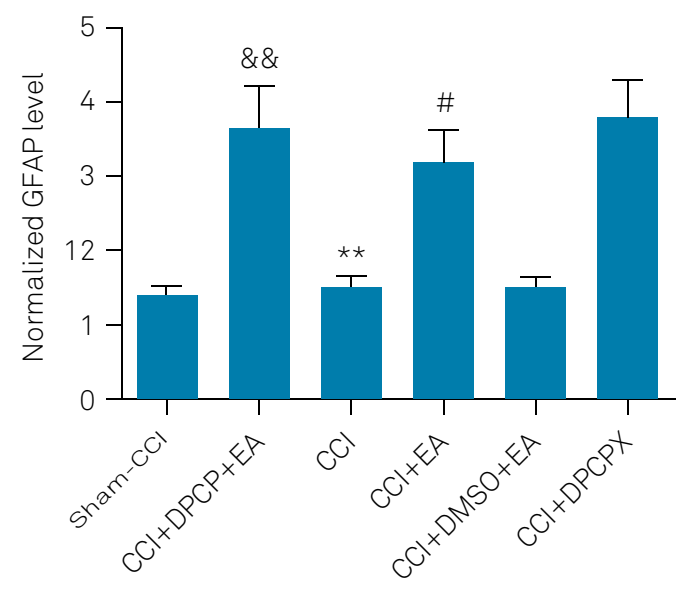

Figure 3. Changes in GFAP expression in the L4-L6 spinal dorsal horn after different treatments on day seven after CCI. (A) Representative Western blots of GFAP in the L4-L6 spinal dorsal horn on day seven after CCI. $\beta$-actin was used as a loading control. (B) Quantification analysis of the optical density of these bands. Columns represent means \pm SEM for five separate experiments. ( $\&$ \& $<0.01$, compared with the Sham-CCI group; ${ }^{* *} p<0.01$, compared with the CCl group. ${ }^{*} p<0.05$, compared with the CCI+DMSO+DPCPX group).

showed no difference $(\mathrm{p}>0.05)$. The CCI+DPCPX group (3.74 $\pm 1.19)$ showed a higher level of GFAP expression, with no difference compared with CCI group ( $p>0.05$, Figure 3 ).

\section{Effects of intrathecal injection of DPCPX on cytokine content in the dorsal horn of L4-L6 spinal cord}

The levels of IL- $1 \beta$, IL- 6 and TNF- $\alpha$ were significantly increased in the CCI group $(20.23 \pm 0.93,35.27 \pm 2.76$ and
$98.96 \pm 7.52$, respectively) compared with the Sham-CCI group $(8.37 \pm 1.14,15.05 \pm 2.28$ and $53.23 \pm 4.21$, respectively) $(\mathrm{p}<0.01$, Figure $4 \mathrm{~A}, \mathrm{~B}$ and $\mathrm{C})$. A significant reduction in IL-1 $\beta$, IL-6 and TNF- $\alpha$ was observed in the CCI+EA group $(12.66 \pm 2.09$, $18.48 \pm 2.78$ and $61.32 \pm 11.34$, respectively) compared with the CCI group $(\mathrm{p}<0.01)$, suggesting that the expression of these cytokines is suppressed by EA treatment (Figure 4A, $\mathrm{B}$ and $\mathrm{C}$ ). Moreover, TNF- $\alpha$ was significantly higher in the 
IL-1 $\beta$

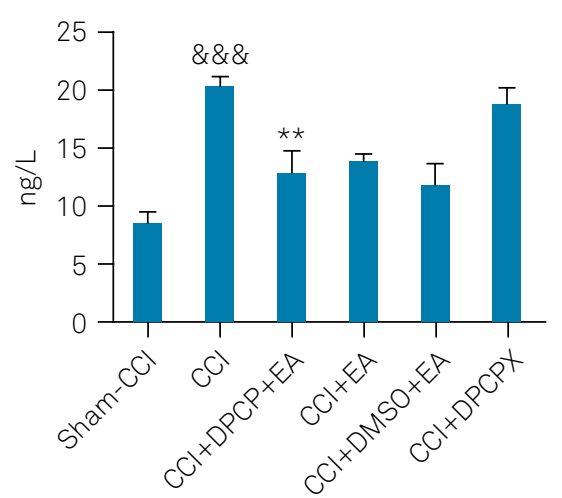

B

IL-6

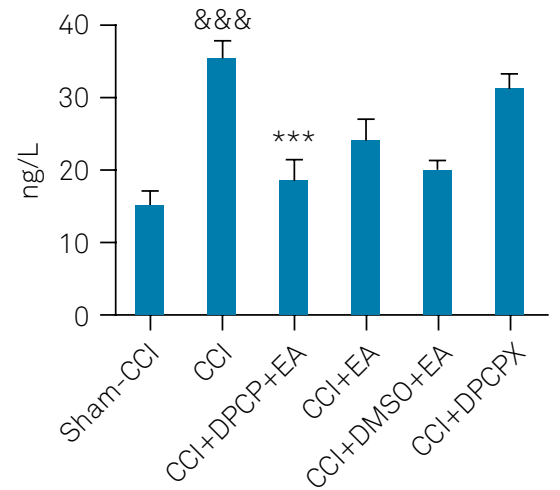

C

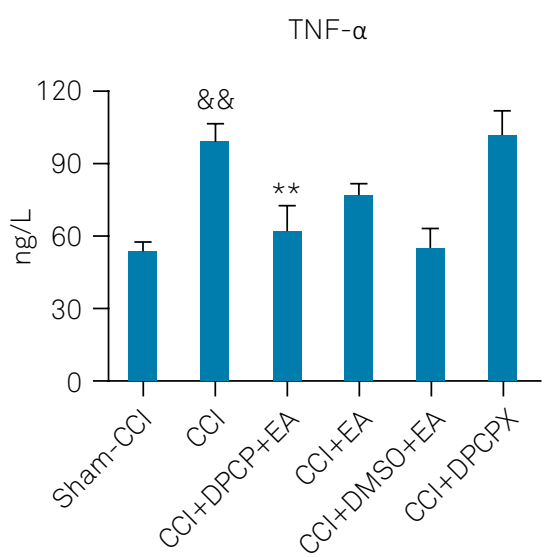

Figure 4. (A) IL-1 $\beta$ expression (B) IL-6 expression and (C) TNF- $\alpha$ expression in the L4-L6 spinal dorsal horn after different treatments on day seven after CCI. Cytokine proteins were quantified by standard ELISA ( $\&$ \& $<0.01$, \&\&\& $<0.001$, compared with the Sham-CCl group; ${ }^{* *} \mathrm{p}<0.01,{ }^{* \star} \mathrm{p}<0.001$, compared with the CCl group; $\mathrm{*}<0.05$, compared with the CCI+DMSO+EA group).

$\mathrm{CCI}+\mathrm{DPCPX}+\mathrm{EA}$ group $(76.93 \pm 5.24)$ in comparison with the CCI+DMSO+EA group $(54.57 \pm 8.16, \mathrm{p}<0.05$, Figure $4 \mathrm{C})$. The CCI+DMSO+EA group did not differ from the CCI+EA group $(p>0.05)$. These results suggested that $A 1 R$ is involved in EA-induced TNF- $\alpha$ suppression. The CCI+DPCPX group showed a high level of cytokine expression, with no difference from the CCI group-suggesting that DPCPX alone did not influence CCI-induced cytokine upregulation (Figure 4A, B and C).

\section{DISCUSSION}

In the present study, we administered intrathecal injections of DPCPX, a selective A1R antagonist, and examined the roles of A1R in EA using a CCI-induced neuropathic pain model. Our findings showed that DPCPX reversed the antinociceptive effects of EA, and A1R is involved in the antinociceptive effects of EA. The EA inhibited astrocyte activation in the spinal dorsal horn, and the DPCPX reversed this effect of EA, suggesting that A1R contributes to the EA effect on CCI-induced astrocyte activation in the spinal dorsal horn. Moreover, EA suppressed the elevated expression of TNF- $\alpha$ in the spinal dorsal horn after CCI, and this effect was abolished by DPCPX. These results suggest that A1R contributes to EA-mediated inhibition of astrocyte activation as well as TNF- $\alpha$ upregulation during neuropathic pain.

The mechanisms of neuropathic pain have been widely studied. Accumulating evidence has shown that astrocytes and microglia play essential roles in the induction and maintenance of neuropathic pain ${ }^{14}$. Both astrocytes and microglia contribute to the modulation of neuronal and synaptic activity and pain sensitivity; therefore, they may serve as therapeutic targets when treating chronic pain ${ }^{15,16}$.

Astrocytes are the most abundant glial cells in the CNS. In addition to the supportive functions, they play important roles in modulating neuronal synaptic function and neuronal excitability ${ }^{17}$. After painful stimuli and injuries, astrocytes are activated in the spinal cord in response to the released neurotransmitters/neuromodulators and inflammatory mediators. Inhibition of the proinflammatory cytokines released by activated astrocytes attenuates nociception ${ }^{18}$.

A previous study reported that repeated EA treatments could suppress the elevated expression of IL-1 $\beta$ mRNA and TNF- $\alpha$ mRNA, but had no effect on IL-6 mRNA in the CCI mode $^{19}$. Our results showed that EA treatment suppressed the upregulated expression levels of TNF- $\alpha$, IL- $1 \beta$ and IL- 6 protein after CCI injury in the spinal cord. This suggests that EA could suppress the elevated proinflammatory cytokines in the spinal cord after nerve injury, which may contribute to the effect of EA in the treatment of neuropathic pain. The discrepancy in results is due to different acupoints and EA protocols.

The A1R is a Gi/o protein-coupled receptor, and thus inhibits the production of cAMP from ATP, stimulates potassium channels, reduces transient voltage-dependent calcium channels and activates phospholipase C. The A1R can also activate the extracellular signal-regulated kinase pathway, leading to downstream biological effects ${ }^{20}$. Both systemic and local administration of the A1R agonist has analgesic effects ${ }^{21-23}$.

The effects of A1R in acupuncture analgesia have been reported in different models. In the complete Freund's adjuvant-induced inflammatory pain model, adenosine was released during acupuncture in the Zusanli acupoint, and the antinociceptive actions of adenosine required A1R expression, indicating that local A1R around the Zusanli acupoint mediates the effects of acupuncture ${ }^{24}$. In another study, Takano et al..$^{25}$ emphasized that acupuncture or needling in the wrong points did not result in adenosine release, much the same as not rotating the needle. Only when the needle was rotated, instead of being inserted, did adenosine concentration markedly increase ${ }^{25}$. These studies did not 
examine the effect of A1R in the CNS. The AlR antagonist, rolofylline, suppressed EA-mediated analgesia in the complete Freund's adjuvant-induced inflammatory pain model ${ }^{26}$. Fibromyalgia-induced mechanical hyperalgesia was attenuated by EA, and this EA-based effect was abolished by rolofylline ${ }^{27}$. Attenuating the EA upregulation of ASIC3, Nav1.7, and Nav1.8 in both the spinal cord and dorsal root ganglion of fibromyalgia mice may have been one of the mechanisms, and this effect was AlR dependent ${ }^{27}$. In the present study, we examined the effects of A1R in a CCI-induced neuropathic pain model. Our results suggest that an intrathecal injection of the A1R antagonist wiped out the effect of EA-mediated inhibition of astrocyte activation, as well as its induced suppression of TNF- $\alpha$ upregulation.

In summary, we found that spinal A1R contributed to the inhibitory effects of EA on astrocyte activation as well as TNF- $\alpha$ upregulation. Our findings may shed light on the development of therapeutic targets for neuropathic pain.

\section{References}

1. Ji RR, Strichartz G. Cell signaling and the genesis of neuropathic pain. Sci STKE. 2004 Sep;2004(252):reE14.

2. McCleane G. Pharmacological management of neuropathic pain. CNS Drugs. 2003;17(14):1031-43. https://doi.org/10.2165/00023210-200317140-00003

3. Colombo B, Annovazzi PO, Comi G. Medications for neuropathic pain: current trends. Neurol Sci. 2006 May;27(S2 Suppl 2):S183-9. https://doi.org/10.1007/s10072-006-0598-7

4. World Health Organization. Acupuncture: review and analysis of reports on controlled clinical trials. Geneva: World Health Organization; 2003.

5. Fredholm BB, IJzerman AP, Jacobson KA, Klotz KN, Linden J. International Union of Pharmacology.XXV. Nomenclature and classification of adenosine receptors. Pharmacol Rev. 2001 Dec;53(4):527-52.

6. Calker D, Müller M, Hamprecht B. Adenosine regulates via two different types of receptors, the accumulation of cyclic AMP in cultured brain cells. J Neurochem. 1979 Nov;33(5):999-1005. https://doi.org/10.1111/j.1471-4159.1979.tb05236.x

7. Fiebich BL, Biber K, Gyufko K, Berger M, Bauer J, Calker $D$. Adenosine $A 2 b$ receptors mediate an increase in interleukin (IL)-6 mRNA and IL-6 protein synthesis in human astroglioma cells. J Neurochem. 1996 Apr;66(4):1426-31. https://doi.org/10.1046/j.1471-4159.1996.66041426.x

8. Schwaninger M, Neher M, Viegas E, Schneider A, Spranger M. Stimulation of interleukin-6 secretion and gene transcription in primary astrocytes by adenosine. J Neurochem. 1997 Sep;69(3):114550. https://doi.org/10.1046/j.1471-4159.1997.69031145.x

9. Ciccarelli R, Di lorio P, Ballerini P, Ambrosini G, Giuliani P, Tiboni GM et al. Effects of exogenous ATP and related analogues on the proliferation rate of dissociated primary cultures of rat astrocytes. J Neurosci Res. 1994 Dec;39(5):556-66. https://doi.org/10.1002/jnr.490390507

10. Bennett GJ, Xie YK. A peripheral mononeuropathy in rat that produces disorders of pain sensation like those seen in man. Pain. 1988 Apr;33(1):87-107. https://doi.org/10.1016/0304-3959(88)90209-6

11. Liu MR, Xiao RF, Peng ZP, Zuo HN, Zhu K, Wang SM. [Effect of acupuncture at "Zusanli" (ST 36 and "Taichong" (LR 3) on gastrointestinal hormone levels in rats with diarrhea type irritable bowel syndrome]. Zhen Ci Yan Jiu. 2012 Oct;37(5):363-8. Chinese.

12. Sun S, Cao H, Han M, Li TT, Zhao ZQ, Zhang YQ. Evidence for suppression of electroacupuncture on spinal glial activation and behavioral hypersensitivity in a rat model of monoarthritis. Brain Res Bull. 2008 Jan;75(1):83-93. https://doi.org/10.1016/j.brainresbull.2007.07.027

13. Hargreaves K, Dubner R, Brown F, Flores C, Joris J. A new and sensitive method for measuring thermal nociception in cutaneous hyperalgesia. Pain. $1988 \mathrm{Jan} ; 32(1): 77-88$. https://doi.org/10.1016/0304-3959(88)90026-7

14. Gao YJ, Ji RR. Chemokines, neuronal-glial interactions, and central processing of neuropathic pain. Pharmacol Ther. 2010 Apr;126(1):56-68. https://doi.org/10.1016/j.pharmthera.2010.01.002
15. Gosselin RD, Suter MR, Ji RR, Decosterd I. Glial cells and chronic pain. Neuroscientist. 2010 Oct;16(5):519-31. https://doi.org/10.1177/1073858409360822

16. O'Callaghan JP, Miller DB. Spinal glia and chronic pain. Metabolism. 2010 Oct;59 Suppl 1:S21-6. https://doi.org/10.1016/j.metabol.2010.07.011

17. Halassa MM, Fellin T, Haydon PG. The tripartite synapse: roles for gliotransmission in health and disease. Trends Mol Med. 2007 Feb;13(2):54-63. https://doi.org/10.1016/j.molmed.2006.12.005

18. Wei F, Guo W, Zou S, Ren K, Dubner R. Supraspinal glialneuronal interactions contribute to descending pain facilitation. J Neurosci. 2008 Oct;28(42):10482-95. https://doi.org/10.1523/JNEUROSCI.3593-08.2008

19. Wang J, Gao Y, Chen S, Duanmu C, Zhang J, Feng X et al. The effect of repeated electroacupuncture analgesia on neurotrophic and cytokine factors in neuropathic pain rats. Evid Based Complement Alternat Med. 2016;2016:8403064. https://doi.org/10.1155/2016/8403064

20. Fredholm BB, Chen JF, Cunha RA, Svenningsson P, Vaugeois JM. Adenosine and brain function. Int Rev Neurobiol. 2005;63:191-270. https://doi.org/10.1016/S0074-7742(05)63007-3

21. Aley KO, Levine JD. Multiple receptors involved in peripheral alpha 2, mu, and A1 antinociception, tolerance, and withdrawal.J Neurosci. 1997 Jan;17(2):735-44. https://doi.org/10.1523/JNEUROSCI.17-02-00735.1997

22. Borghi V, Przewlocka B, Labuz D, Maj M, Ilona O, Pavone F. Formalin-induced pain and mu-opioid receptor density in brain and spinal cord are modulated by $\mathrm{A} 1$ and $\mathrm{A} 2 \mathrm{a}$ adenosine agonists in mice. Brain Res. 2002 Nov;956(2):339-48. https://doi.org/10.1016/S0006-8993(02)03568-0

23. Lima FO, Souza GR, Verri Juniro WA, Parada CA, Ferreira SH, Cunha FQ et al. Direct blockade of inflammatory hypernociception by peripheral A1 adenosine receptors: involvement of the NO/cGMP/ PKG/KATP signaling pathway. Pain. 2010 Nov;151(2):506-15. https://doi.org/10.1016/j.pain.2010.08.014

24. Goldman N, Chen M, Fujita T, Xu Q, Peng W, Liu W et al. Adenosine A1 receptors mediate local anti-nociceptive effects of acupuncture. Nat Neurosci. $2010 \mathrm{Jul} ; 13(7): 883-8$. https://doi.org/10.1038/nn.2562

25. Takano T, Chen X, Luo F, Fujita T, Ren Z, Goldman N et al. Traditional acupuncture triggers a local increase in adenosine in human subjects. J Pain. 2012 Dec;13(12):1215-23. https://doi.org/10.1016/j.jpain.2012.09.012

26. Liao HY, Hsieh CL, Huang CP, Lin YW. Electroacupuncture Attenuates CFA-induced inflammatory pain by suppressing Nav1.8 through S100B, TRPV1, Opioid, and Adenosine Pathways in Mice. Sci Rep. 2017 Feb;7(1):42531. https://doi.org/10.1038/srep42531

27. Yen LT, Hsieh CL, Hsu HC, Lin YW. Targeting ASIC3 for relieving mice fibromyalgia pain: roles of electroacupuncture, opioid, and adenosine. Sci Rep. 2017 Apr;7(1):46663. https://doi.org/10.1038/srep46663 